
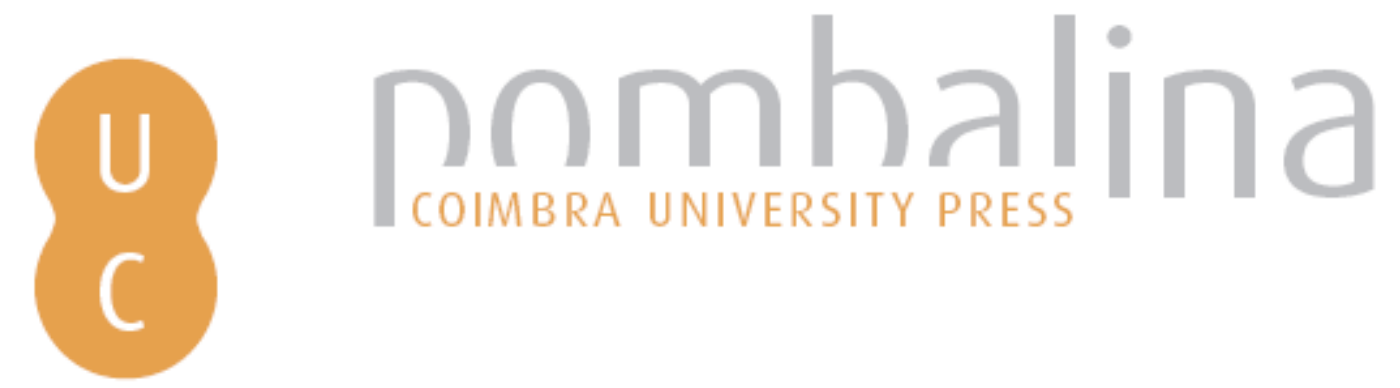

\title{
O colapso da ordenação urbana e o surgimento do labirinto: do mito racional ao labirinto de Buenos Áires no El cantor de tango de Tomás Eloy Martínez
}

\author{
Autor(es): $\quad$ Molina Ahumada, Ernesto Pablo \\ Publicado por: Imprensa da Universidade de Coimbra \\ URL \\ persistente: URI:http://hdl.handle.net/10316.2/36677 \\ DOI: $\quad$ DOI:http://dx.doi.org/10.14195/978-989-26-1015-3_15 \\ Accessed : $\quad$ 26-Apr-2023 09:45:06
}

A navegação consulta e descarregamento dos títulos inseridos nas Bibliotecas Digitais UC Digitalis, UC Pombalina e UC Impactum, pressupõem a aceitação plena e sem reservas dos Termos e Condições de Uso destas Bibliotecas Digitais, disponíveis em https://digitalis.uc.pt/pt-pt/termos.

Conforme exposto nos referidos Termos e Condições de Uso, o descarregamento de títulos de acesso restrito requer uma licença válida de autorização devendo o utilizador aceder ao(s) documento(s) a partir de um endereço de IP da instituição detentora da supramencionada licença.

Ao utilizador é apenas permitido o descarregamento para uso pessoal, pelo que o emprego do(s) título(s) descarregado(s) para outro fim, designadamente comercial, carece de autorização do respetivo autor ou editor da obra.

Na medida em que todas as obras da UC Digitalis se encontram protegidas pelo Código do Direito de Autor e Direitos Conexos e demais legislação aplicável, toda a cópia, parcial ou total, deste documento, nos casos em que é legalmente admitida, deverá conter ou fazer-se acompanhar por este aviso.




IMPRENSA DA

UNIVERSIDADE

DE COIMBRA

COIMBRA

UNIVERSITY

PRESS

\section{NA GÉNESE DAS RACIONALIDADES MODERNAS II}

Em torno de Alberti e do Humanismo

MÁRIO KRÜGER et alii

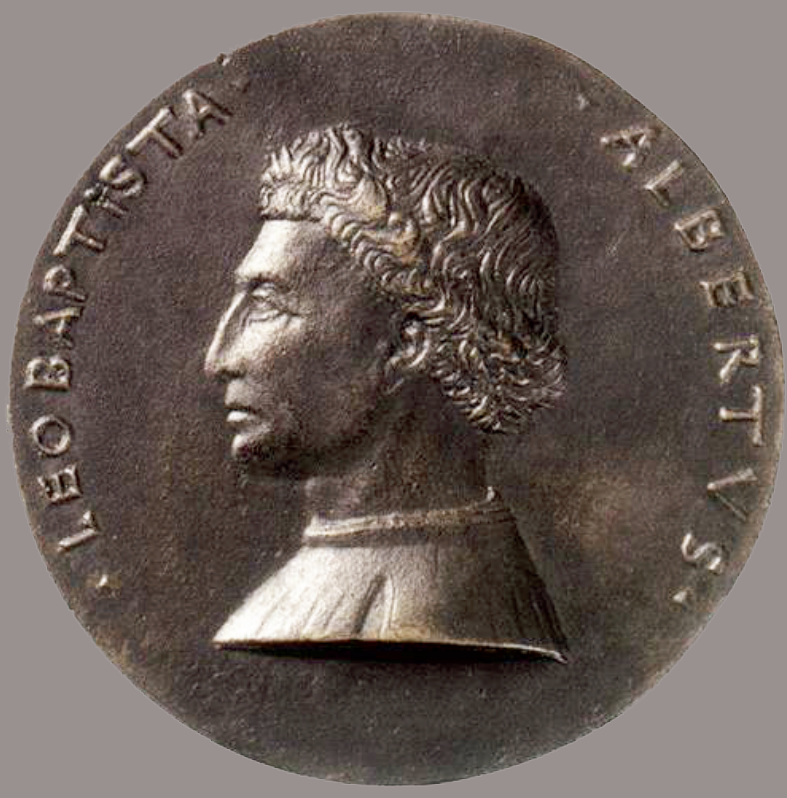




\section{OCOLAPSO DA ORDENAÇÃO URBANA E O}

SURGIMENTO DO LABIRINTO. DO MITO RACIONAL

\section{AOLABIRINTO DE BUENOS AIRES NOELCANTOR DE TANGO DE TOMÁS ELOY MARTÍNEZ}

Ernesto Pablo Molina Ahumada

\section{Resumo}

Este trabalho propõe uma leitura de um romance argentino contemporâneo, investigando os pontos de contato e de divergência em relação à visão projetista da cidade ocidental. Nossa leitura tenta distinguir nessa construção ideológica duas linhas em estado de tensão, o projeto racional e a violência necessária para a sua execução, buscando a harmonização na proposta de Leon Battista Alberti partindo de um discurso controlado sob a retórica técnica-científica do tratado. A proposta de Alberti é examinada em sua tensão constitutiva básica como um sinal de um momento específico da expansão da cultura Europeia Ocidental, que projetada sobre os novos territórios da América envolverá uma complexidade dessa tensão inicial.

Romance; Mito; Cidade; Labirinto

\section{Résumé}

Notre travail propose une lecture d'un roman argentin contemporain, en recherchant les points de contact et de divergence à l'égard de la vision projetée de la ville occidentale. Notre regard essaie de distinguer dans cette construction idéologique deux lignes dans 
une tension, celui-là du dessin rationnel et celui-là de la violence requise pour son implémentation, que cherchent à être harmonisés dans la proposition albertiana à partir d'un discours contrôlé sous la rhétorique scientifique-technique du traité. La proposition de Leon Battista Alberti est recherchée dans sa tension basique constitutive comme signe d'un moment spécifique d'expansion de la culture européenne occidentale que, projetée sur les nouveaux territoires de l'Amérique, ils impliqueront une forme complexe de cette tension initiale.

Roman; Mythe; Cité; Labyrinthe

\begin{abstract}
This work intends an analysis of a contemporary Argentine novel, by means of investigating both contact and divergence points in relation to the designer's view of the western city. Our reading attempts to distinguish, in this ideological construction, two lines in "state of tension", the rational project and the necessary violence for its implementation, looking for the harmonization in Léon Battista Alberti's proposal starting from a speech guided by the scientifical and technical rhetoric of the treaty. The basic constituent tension of Alberti's proposal is analyzed as a sign of a specific moment of the expansion of the Western European culture, which projected over the new territories of America, will involve the complexity of that initial tension.
\end{abstract}

Novel; Myth; City; Labyrint 
A cidade é a realização do antigo sonho humano do labirinto.

Walter Benjamin 378

Nós não sabemos onde o labirinto acaba, nem se ele acaba. Há uma parte externa, além de suas paredes? O leitor será quem decida (veja) se ele tem ou não.

Ricardo Gullón 379

\section{A cidade de Alberti e a ordenação mítica ocidental}

O sono da razão produz monstros, disse Goya. Também labirintos, ajuntamos desde uma perspetiva latino-americana que pretendemos convocar aqui, neste livro que reúne artigos bem perto e longe do continente americano, simultaneamente. Perto, porque as cidades latino-americanas estão ligadas à Europa pela genealogia, isto é, são o resultado da interseção entre o olhar europeu utópico e as condições topográficas, climáticas, políticas e sociais do continente conquistado. Como observa Fernando Aínsa ${ }^{380}$, a extensão e a novidade do novo mundo têm impulsionado o desejo do conquistador, do projetista e do missionário de criar um mundo novo, mas negando a textura particular do continente americano, que persistiu como seu pano de fundo e seu solo. América foi imaginada como uma terra desconhecida e inédita, que "era una invitación a conquistarlo y a 'bautizarlo' con palabras nuevas, apasionantes 'grafías' con las que se construyeron progresivamente los paisajes arquetípicos con que ahora se lo caracteriza."381

Mas o ato de possuir dos territórios foi amalgamado em breve com esta mecânica da escrita que validava a conquista do território 382 e criou uma

378 WALTER BENJAMIN, Libro de los pasajes. Madrid, Akal, [1927] 2005. La traducción es nuestra.

379 RICARDO GULLÓN, Espacio y novela. Barcelona, Bosch, 1980. La traducción es nuestra.

380 Del topos al logos. Propuesta de Geopoética. Madrid, Iberoamericana, 2006.

381 Ibidem, p. 37.

382 Cf. ÁNGEL RAMA, La ciudad letrada. Montevideo, Arca, 1998; JOSÉ LUIS ROMERO, Latinoamérica: las ciudades y las ideas. Buenos Aires, Siglo XXI, 2004 [1986]. 
aliança íntima entre a palavra e o espaço. As cidades latino-americanas são uma amálgama de elementos materiais, utopia e signos, planos sobrepostos que definem sua identidade complexa e instável e que conferem um papel privilegiado tanto ao projetista como ao letrado, ambos criadores do urbano. Esta preeminência do projetista aparece no tratado De re aedificatoria (1482) de Alberti ${ }^{383}$, especificamente no proêmio, onde o autor dá ao arquiteto um lugar transcendente não só na construção do cosmo urbano senão também do cosmo social. De acordo com Paolo Rossi ${ }^{384}$, a intenção explícita - comum a outros tratados do XV e XVI - de misturar atividade técnica e conhecimento científico é suportada por este louvor da figura heroificada do arquiteto como uma metáfora da síntese entre ciência, técnica e trabalho manual e, além disso, como uma personagem principal de um texto (o Tratado) que expressa uma mudança fundamental na cultura: a preocupação por uma construção teórica do urbano, a substituição de um regime material por outro simbólico, um regime de signos que constrói um modelo da cidade e um ponto de vista autorizado, isto é, com plena autoridade para validar epistemologicamente um saber/fazer sobre o mundo (Furlan, 2013). Neste ponto é onde a cidade utópica torna-se pensável, mas também a cidade não utópica, a não-cidade como possibilidade imaginária alternativa que constantemente ameaça com sua desordem essa construção racional.

Por esse motivo Alberti situa-se na gênese do pensamento moderno: porque participa da cristalização que Enrique Dussel ${ }^{385}$ designa "o mito (europeu) da modernidade", definido como a implantação de certa visão de mundo que se torna universal e global, constituindo a um tempo só como sua periferia as outras culturas. A cidade torna-se, a este nível, o artefato privilegiado que garante a extensão efetiva da narração ou mito ocidental e devém mito mobilizador do Ocidente ${ }^{386}$. Mas a cidade

383 LEON BATTISTA AlBERTI, De Re Aedificatoria. Madrid, Akal, 1991.

384 PAOLO ROSSI, Los filósofos y las máquinas. 1400-1700. Barcelona, Labor, 1970 [1966].

385 ENRIQUE DUSSEL, "Europa, modernidad y eurocentrismo" en Lander, Edgardo (comp) La colonialidad del saber: eurocentrismo y ciencias sociales. Perspetivas Latinoamericanas. Bs. As, CLACSO, 2000, pp. 41-53.

386 OLIVER MONGIN, La condición urbana. La ciudad a la bora de la mundialización. Bs. As, Paidós, 2006. 
projetada por Alberti escapa da desordem e do labiríntico porque tudo isso é relegado para o lugar do negado ou desnecessário, e prevalece pelo contrário aquilo que é necessário (neccesitas), confortável (commoditas) e agradável (voluptas). Ruas largas, clima moderado, disposição calculada, tudo isso concentra-se nesta cidade projetada e orientada para o necessário e belo (a concinnitas de Alberti), qualidades que são harmonizadas em torno de um todo orgânico, em analogia com o organismo dos cidadãos em um nível microscópico e com o Estado no nível macroscópico. A ordenação da cidade reproduz e garante a ordenação do mundo, e vice-versa. A arquitetura aparece como a chave e a senha que avalia essa classificação, mas no coração dessa construção racional albertiana reside o paradoxo da modernidade: a existência de um núcleo racional que depende de um processo de violência exercida efetivamente para transformar essa projeção em real. Esta tensão está na base mesma desse pensamento de Alberti, como aponta Aluffi Begliomini:

"La consciencia y la denuncia de los aspetos absurdos e inquietantes de la realidad por un lado, y por otro la contemplación y la construcción de un mundo racional y armónico, son dos actitudes que se entrecruzan y retornan invariablemente en la obra de Alberti, y que son la base de su pensamiento y de su personalidad. Están presentes contemporáneamente en todo momento, incluso cuando uno domina y prevalece sobre el otro." 387

O cogito ego na base do mito racional moderno supõe a violência do ego conquiro aplicada sobre o Outro, que se torna seu duplo e seu fantasma. Neste ponto, a tensão entre a geografia americana e as formas pré-colombianas de organização territorial por um lado, e a ordenação urbana europeia introduzida desde 1492 por outro aparecem como exemplo inevitável, porque é dessa fricção no coração mesmo do projeto moderno que ganha realidade a condição instável das cidades latino-americanas.

387 Cf. JAVIER RIVERA, "Prólogo" en LEON BATTISTA ALBERTI, De Re Aedificatoria. Madrid, Akal, 1991, p. 18. La traducción es nuestra. 


\section{O tabuleiro e o labirinto}

Dissemos que na visão humanista de Alberti coexistem dois paradigmas ou visões de mundo simultâneas e contraditórias, particularmente visíveis se nós confrontamos seus tratados sobre pintura, escultura e arquitetura com suas obras de caráter literário: torna-se visível ali um conflito entre um paradigma racional versus um paradigma do absurdo ${ }^{388}$ ou, de acordo com a profunda análise que desenvolve Francesco Furlan ${ }^{389}$, mostra-se uma tensão entre gêneros que mascara abordagens diferenciadas epistemologicamente no mapa da proposta filosófica de Alberti. De acordo com nossa perspetiva, essa tensão contínua é expressão do próprio nó insolúvel do mito modernizante como observamos anteriormente, tensão que se prolonga também ao mesmo tempo sobre os territórios americanos como um paradoxo persistente desde a sua fundação.

Esta tensão, tão sutilmente presente em Alberti, como é projetada sobre os textos artísticos contemporâneos na América Latina? Na literatura argentina, por exemplo: como é lido o núcleo urbano referencial da cidade ordenada e planeada?

A arte é, talvez, a linguagem da cultura capaz de fazer constar esta condição relativa e precária, sempre no ar, da ordenação urbana racional. Em particular, usando metáforas espaciais como o tabuleiro ("damero") e o labirinto, funcionando algumas vezes como pólos de oposição e outras como anverso e reverso dentro da mesma cidade. Esta última possibilidade é explorada de forma notável por um romance contemporâneo do escritor argentino Tomás Eloy Martínez, El cantor de tango. Diz o romance no seu inicio:

"Con el paso de los días, fui aprendiendo que Buenos Aires, diseñada por sus dos fundadores sucesivos como un damero perfecto, se había

388 MARIANA SVERLIJ, "La razón y el absurdo en la obra de Leon Battista Alberti" en Studia Aurea, 6, 2012, pp. 155-177.

389 Curso de posgrado ofrecido por el Dr. Franceso Furlan, "Leon Battista Alberti. Rasgos de una nueva racionalidad", octubre de 2013, Facultad de Arquitetura-Facultad de Artes y Facultad de Lenguas, Universidad Nacional de Córdoba, Córdoba, Argentina. 
convertido en un laberinto que sucedía no sólo en el espacio, como todos, sino también en el tiempo."390

O romance narra a pesquisa dum estrangeiro após dois passos de um cantor de tango misterioso que, como dizem aqueles que foram capazes de ouvir-lhe, canta melhor do que o Gardel. E poucos foram capazes de ouvi-lo porque suas aparições são tão inesperadas e irregulares, que logo tornam ao cantor em uma figura fantasmagórica e a história de sua busca, em uma tarefa de investigação tingida com o gênero literário policial. O particular é que essa pesquisa se inicia através das sendas regulares do "damero" de Buenos Aires (ruas reconhecíveis, monumentos e sítios icónicos, marcos turísticos) e ganha complexidade à medida que o protagonista do romance revela os segredos que estão escondidos lá. Deste modo, a cidade acaba-se tornando um labirinto intrincado apesar de ter sido construída segundo um traço regular; ela se distancia do plano para devir um espaço dinâmico com volume, desenvolvido ao longo do tempo, incitadora de coreografias heroicas particulares: segundo Hermann Kern, em todo labirinto "The walls themselves are unimportant. Their sole function is to mark a path, to define choreographically, as it were, the fixed pattern of movement."391

Existe uma operação análoga entre o olhar científico e o olhar da literatura sobre a cidade neste sentido: a construção de um modelo metafórico que descreve e inventa a realidade material de que parte, permitindo pensar em diferentes ordenações retóricas (científicas e artísticas) que apelam para a produtividade de um tropo mesmo para construir um ordenamento de realidade ${ }^{392}$. A diferença reside em que, enquanto a visão projetista de Alberti orienta as contribuições da geometria, matemática, retórica ciceroniana e estética para uma totalidade harmônica metaforicamente equiparada com o organismo vivo, a cidade metafórica

390 TOMÁS ELOY MARTíNEZ, El cantor de tango. Bs. As, Emecé, 2004, p. 49.

391 HERMANN KERN, Through the Labyrinth. Designs and meanings over 5000 years. Munich-London-New York, Prestel, 2000, p. 23.

392 SILVIA BAREI, "Perspetivas retóricas", en: Silvia Barei y Pablo Molina, Pensar la cultura I: Perspetivas retóricas. Córdoba, GER, 2008. 
que inventa o romance de Tomás Eloy Martínez apela para a explosão desses componentes e explora, não obstante, sua insuficiência, sua ineficácia, o reverso invisível e contraditório que persiste nesta visão racional do projetista. Como uma hipótese, podemos considerar até mesmo que o romance oferece a imagem desse caráter labiríntico como um rasgo emergente engendrado no coração mesmo deste modelo mítico racional.

Isto aparece claramente no romance na metáfora do labirinto invertido, ou seja, aquele que se projeta a partir dos espaços vazios entre as paredes divisórias do labirinto. Mas a complicação do desenho deriva também do caráter policêntrico da geografia, invalidando assim qualquer possibilidade de uma única trajetória, autorizada ou desejável. Deste modo, Buenos Aires torna-se um território móvel, continuamente descentrado por causa do nomadismo do herói que é quem ativa a cidade. Não há espaço aqui para esse olhar de cima do projetista, o olho totalizante e onividente que Michel de Certeau393 equipara metaforicamente a ânsia de Dédalo, em oposição com as estratégias inteligentes e desobedientes dos transeuntes em seus efêmeros caminhos através da cidade. A viagem do herói, como aquela de Ulisses no poema homérico, exige o enceguecimento deste olho totalitário para continuar, o olho do ciclope Polifemo, que também é o olho do deus Poseidon. Desta forma, o romance de Martinez mostra como o desenho geométrico projetado revela-se como um labirinto, e como essa condição complicada se torna uma maldição ao mesmo tempo em que fonte de produtividade (política, artística, memorialística) da América Latina cidade:

"Eso es Buenos Aires [...] : un delta de ciudades abrazado por una sola ciudad, breves ciudades anoréxicas dentro de esta obesa majestad única que consiente avenidas madrileñas y cafés catalanes junto a pajareras napolitanas y templetes dóricos y mansiones de la Rive Droite, más allá de todo lo cual -le había insistido el taxista- están sin embargo el mercado de hacienda, el mugido de las reses antes del sacrificio y el

393 MICHEL DE CERTEAU, La invención de lo cotidiano. 1. Artes de hacer. México, Univ. Iberoamericana, 1997. 
olor a bosta, es decir el relente de la llanura, y también una melancolía que no viene de parte alguna sino de acá, de la sensación de fin del mundo que se siente cuando se mira los mapas y se advierte cuán sola está Buenos Aires, cuán a trasmano de todo."394

A ambivalência do labirinto encontra-se neste jogo entre contorno e conteúdo, segundo o qual o complexo arquitetônico é uma circunstância do padrão de movimento que ocorre dentro do labirinto e segurá-lo, como se fossem aqueles espaços de possíveis coreografias os que constituem realmente o labirinto. Esta inversão complica a metáfora mítica do labirinto como construção complexa e limitada, para construir aquela do território móvel ativado pelos percursos dos personagens. A existência do labirinto invertido no romance que analisamos destaca-se pela sua condição de cenário tenso sobreposto a um fundo dolorido e não apaziguado, uma cidade de infinita crueldade e violência sem interrupção que esconde, após os nomes de suas ruas e praças, uma longa série de crimes impunes que revelam a face mais inóspita da cidade. A viagem do herói do romance de Martinez propõe uma hipótese de leitura sobre o sentido que encerra o labirinto construído pelo cantor através de suas aparições, mas também construído pela própria desordem que está conquistando a Buenos Aires conforme se aproxima dezembro de 2001, quadro temporal em que os eventos do romance acontecem. dezembro de 2001 é um momento traumático para a Argentina pela violência da explosão social que ocasionou a situação de crise política profunda por vários meses. O clima, o humor das pessoas, a rotina urbana, tudo se torna conflituoso aos olhos do estrangeiro que descobre que Buenos Aires tornou-se com o passar das horas, um labirinto social.

O labirinto de Buenos Aires neste romance representa de certa forma o inverso do mito da cidade planeada, porque nasce como a escrita desobediente dos sujeitos à margem da escrita oficial. Se a cidade latino-americana, como assinala Ángel Rama ${ }^{395}$, nasce da confluência entre o

394 TOMÁS ELOY MARTÍNEZ, Ibidem, p. 63.

395 ÁNGEL RAMA, Ibidem, 
gesto de uma violência efetivamente realizada (a espada) e o signo que confere-lhe identidade simbólica (a letra), poderíamos reconhecer uma dupla articulação que torna visível a profunda compenetração do tabuleiro com o labirinto e a ordenação racional com a violência irracional. Walter Benjamin intuía com grande acerto isto quando ele propôs que todo documento da cultura é simultaneamente um documento da barbárie. Da mesma forma nós temos pensado com Dussel o paradoxo da modernidade e, também, o próprio significado do romance que aposta pelo confronto entre esta representação ordenada da cidade, imagem de longa permanência e poder na memória da cultura ocidental, e a exploração de seu reverso labiríntico nas dobras do tabuleiro, iluminando seus lugares vazios ou esvaziados por causa do olvido imposto e a violência da memória oficial. Um exemplo claro desta tensão entre o anverso e reverso urbano aparece na novela na cena em que o herói visita e fica extraviado no bairro labiríntico de Parque Chas ${ }^{396}$. O herói, que tem sido impulsionado lá pela pista do cantor, se introduz sozinho e desamparado pela área inóspita cujo desenho regular (circular) devém, no entanto, uma zona de "alta densidade" que torna confusa a distinção entre a realidade da cidade e as ficções que falam sobre ela:

"Cientos de personas se han perdido en las calles engañosas de Parque Chas, donde parece estar situado el intersticio que divide la realidad de las ficciones de Buenos Aires. En cada gran ciudad hay, como se sabe, una de esas líneas de alta densidad, semejante a los agujeros negros del espacio, que modifica la naturaleza de los que la cruzan."397

\section{Descrever e escrever a cidade}

Quando Benjamin sugere que a cidade é a materialização do antigo sonho humano do labirinto, a ideia inquieta por causa da significação que

396 Site oficial do bairro na Internet: http://www.parquechasweb.com.ar/ [10/08/2012]

397 TOMÁS ELOY MARTíNEZ, Ibidem, pág. 164. 
adota esta metáfora mítica na atualidade. Nós associamos o labiríntico com a desordem, o irracional, confuso e intrincado, talvez também com a periculosidade e a prisão. De acordo com Paolo Santarcangelli ${ }^{398}$ e Karl Kerényi ${ }^{399}$, existem ao longo da história da cultura tempos de floração e invisibilidade daquela metáfora do labirinto, dependendo da direção que cada sociedade atribui-lhe e do modelo com o qual confronta-lo. Em alguns casos, o labirinto tem a forma do intrincado irracional, mas em outros, de desenho perfeitamente regular que propõe um desafio lógico para sua resolução. Após um longo período de boom medieval entre 1100 e 1300 d.C., a importância da figura do labirinto diminuiu até seu desaparecimento no século XVI e reapareceu na conceção dos jardins cortesãos do século XVII e XVIII. O barroco tornou-o, de fato, um tema obsessivo, e a racionalidade do século XIX, eminentemente anti-labiríntica, restringiu-o ao âmbito dos jogos infantis. O traçado de um labirinto representa um gesto de racionalização do espaço. Ainda o labirinto de uma só via, construído por uma única senda em linha reta até o fim da história (como, por exemplo, no conto "A morte e a bússola" ["La muerte y la brújula"] de Jorge Luis Borges), dialoga com outros labirintos mais complexos, policêntricos ou sem centro, com múltiplas possibilidades de viagens e resolução. Ou seja, que não só as cidades americanas nasceram como um gesto de escrita do espaço, senão, em essência, toda cidade é um efeito da escrita. Aí reside o poder dos epigrafes que abrem o nosso artigo e também a validade de uma leitura em perspetiva mítica e literária da cidade: tanto as cidades ordenadas de Alberti como as cidades regulares planeadas pelos agrimensores e arquitetos em território americano no século XVI. E também aquelas cidades que descreve T. Eloy Martínez como nascidas a partir da fricção entre trajetórias sobrepostas que delineiam uma cartografia complexa e não apaziguada; todas estas cidades respondem ao mesmo princípio da racionalização (e violência) implicado no estabelecimento desta modelagem.

398 PAOLO SANTARCANGELLI, El libro de los laberintos. Madrid, Siruela, 1997.

399 KARL KERENYI, En el laberinto. Madrid, Siruela, 2006. 
Descrição implica, portanto, a escrita do espaço, sua organização num sistema discreto que determina as formas da ordenação e a desordem cultural. Mas se em De re aedificatoria Alberti orienta as estratégias retoricas e cognitivas para processos de classificação, definição e descrição como sustento do discurso científico do Tratado, no romance El cantor de tango se apela bastante para a confusão deliberada destas retóricas (científica, mítica, aquela do discurso turístico, da vida cotidiana, etc.) para construir a imagem de uma cidade extensa e profunda, geologicamente complexa com seus múltiplos planos e níveis, sujeita a conflito na luta entre aquilo que se esquece e se lembra, intensamente conhecida e desconhecida ao mesmo tempo. Espaço mítico ideal, em uma palavra, para que um herói casual experimente uma viagem iniciática que, longe de qualquer caminho épico, assegure a aquisição de conhecimento, mas não uma mudança transcendental nesse mundo de partida, onde fica intacta essa fecunda desordem inicial. A imagem do labirinto torna visível a existência destas lógicas em tensão e, portanto, não só no desenho, senão também nos olhos de quem olha está a chave para esquadrinhar a complexidade do processo de racionalização: "Onde o labirinto acaba?", pergunta Ricardo Gullón ${ }^{400}$; onde o leitor determina, ele responde e nós respondemos com ele.

Alberti é, além dum criador, um leitor notável do seu tempo que sistematiza e sintetiza um complexo sistema cultural através de uma particular modelação do espaço proposta como desejável nos seus tratados de arquitetura. O paradoxo emerge no momento de ler sua produção literária 401 em paralelo. Sua cidade é, neste sentido, uma hipótese de leitura que se enuncia numa destas formas (a arquitetônica) como vereda da escrita desejável para ordenar o universo humano através da gestão racional dos elementos da cidade. Mas seu projeto implica, no profundo e tal como evidencia a leitura em contraponto da sua obra literária, a coexistência do anverso racional com um reverso violento, porque a implantação do próprio projeto racional (no qual ele está imerso) requer isso como sua

400 RICARDO GULLÓN, Ibidem,

401 MARIANA SVERLIJ, Ibidem, 
condição de possibilidade. $\mathrm{O}$ mito moderno ocidental, mobilizado a partir deste artefato mítico moderno que é a cidade, traslada esse modelo para todo o mundo e faz, pela primeira vez na história, traço global. Estritamente falando, o "mundo ocidental" não existe antes deste processo de globalização que desenvolveu a Europa ocidental a partir de 1492 . Mas lá também, paradoxalmente, prevalece junto ao projeto racional, "o lado mais sombrio da Renascença" segundo expressa Walter Mignolo. ${ }^{402}$

A cidade de Buenos Aires, no romance que analisamos, torna visível, mais do que a limitação deste projeto, seu estatuto íntimo de figura paradoxal. Como o deus latino Janus, Buenos Aires é construída em El cantor de tango com duas faces: uma pitoresca e tranquila que alimenta o turismo e a memória oficial; e outra terrível de morte, violência e intolerância que é o substrato das suas ruas e sua atmosfera. Também como o deus Janus, o semblante de Buenos Aires aponta para dois lugares diferentes: no seu passado de modelo regular e aparência pacífica (o tabuleiro [damero]); e no seu presente e seu futuro de labirinto intrincado e insolúvel. O labirinto emerge da cidade planeada, porque isso sempre existiu; não é tanto o efeito de uma invasão ou uma infecção, senão mais bem a irrupção desde o interior das desobediências, as deslealdades e as divergências contra a hegemonia, seja planeada ou não.

402 WALTER MIGNOLO, The Darker Side of the Renaissance: Literacy, Territoriality, and Colonization. Ann Arbor, The University of Michigan Press, [1995] 2003. 